International Journal of Natural Science and Reviews
(ISSN:2576-5086)

\title{
Disaster management strategy for avoiding the future losses by a slope failure at Nanhuan road, Fuxin area, Northeast China
}

\author{
Kaleem Ullah Jan Khan ${ }^{1}$, Changming Wang ${ }^{1 *}$, Zhu Liang ${ }^{1}$, Lixin Zhang ${ }^{2}$ \\ ${ }^{1}$ College of Construction Engineering, Jilin University, Changchun 130021, P.R China. \\ ${ }^{2}$ Liaoning Traffic Planning and Design Institute, Shenyang 110005, China
}

\section{ABSTRACT}

Many surrounding areas in the vicinity of failed slope at Nanhuan road, Fuxin area, Northeast China are witnessed as the signs of ${ }^{*}$ Correspondence to Author: disaster. The observed settlement as wastage of an active mass Changming Wang

in the area has been observed after the excessive precipitation College of Construction Engineerinin 2012 (May to October) which caused infrastructural damages g, Jilin University, Changchun 1300 (Roads at the top and bottom of the failure zone), agricultural fields and residential areas. Therefore, the paper proposes examining this subject. An extensive field investigation was conducted in the area of Fuxin, west of Liaoning province China. It is recommended and suggested that a series of disaster prevention and both structural and non-structural mitigation measures with the involvement of government and local community are required, to be prepared in advance for avoiding 21, P.R China.

the future economic loss as well as the impending disaster in the area. This paper also highlights the need of investigation in response mechanism and forward planning for awareness initiatives: to avoid the future hazard in the remotest failure zones of Fuxin area, Northeast China.

Keywords: Landslides; Fuxin; Disaster; Management strategy

How to cite this article:

Kaleem Ullah Jan Kha, Changming Wang, Zhu Liang, Lixin Zhang. Disaster management strategy for avoiding the future losses by a slope failure at Nanhuan road, Fuxin area, Northeast China. International Journal of Natural Science and Reviews, 2020; 5:15.

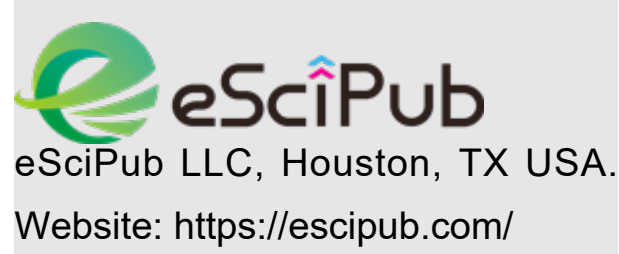




\section{Introduction}

Disaster is basically not a crisis but a situation in which most important decisions should be taken in a short duration of time including procedures of management and maintenance under major technical conditions involving loss of lives $[1,6]$ and damage of infrastructure. Many researchers have defined disaster in terms of dependency upon its nature of occurrence ${ }^{[2,3,6,7,8]}$. The disaster occurred due to a slope failure in Fuxin area, Northeast China is a kind of geological disaster having devastating impacts on human lives, infrastructure and vegetative fields in the surroundings, which can cause a great economic loss.

It is observed in the field investigation that the moment of slope failure in Fuxin area is in horizontal downward direction (from crest to toe) which converts the gravitational potential energy into kinetic energy causing diastrophism and denudation in the form of debris and landslide, based on the mechanism of mass movement in the area. There is no doubt that the instability of slope is mainly due to the disturbance in equilibrium between the shearing stress and strength followed by various exo-indogenetic forces. However, it should be taken into consideration that the slope failure cannot be caused only by one factor, though a single factor can play a vital role in failure at specific time and place. In the present case of fragile environment in Fuxin area, the slope is observed to be governed by various causative factors to failure.

In order to neutralize all the negative impacts which results from disasters are not commonly agreeable. However, the impacts of those disasters on infrastructure and lives can be minimized by efforts and planning. In this regard, the effective strategy for disaster management plays an important role as a key element for good governance ${ }^{[4]}$.

Unplanned artificial filling of slope in the failure zone of Fuxin, anthropogenic interventions, unplanned design of infrastructure and urban planning in the area further extend the vulnerability of failure and expose the people residing in the surroundings to the risks employed by natural hazards. For this purpose, an urgent emergency planning and arrangements with voluntary local communities and private entrepreneurs by involving government endeavours should carried out to respond the occurrence of disaster.

This research emphasizes that an urgent treatment is needed on priority basis for the sliding at Nanhuan road, Fuxin area, Northeast China followed by a slope failure (eventualized by natural degradational and unplanned artificial filling processes together with atmospheric precipitation and anthropogenic activities), which cause a potential threat to the infrastructure and people residing in surroundings of the failure zone.

\section{The area}

\subsection{Geography and Climate}

The area under study is located at Nanhuan road, Fuxin city, situated to the west of Liaoning province, Northeast China (Figure. 1). The west of the area is adjacent to Chifeng, In-ner Mongolia and is mainly controlled by the airflow from Xipoliang to Inner Mongolia. The max-imum and uniform wind speed is $7 \mathrm{~m} / \mathrm{s}$ and $1-3 \mathrm{~m} / \mathrm{s}$ respectively. Xihe river in the west and Guanshan river is located southward of the failure zone.

The maximum daily and the average annual rainfall recorded in this area ranges $147 \mathrm{~mm} /$ day and from $480-600 \mathrm{~mm} /$ year respectively, with high annual precipitation rate in this region. The intense prolong rainfall events particularly in the rainy season are associated with rainstorms level of $53 \mathrm{~mm} /$ hour, which considers as an unfavourable characteristic of rainfall and is identified as the frequent cause of landslide. The climate of this area belongs to the northern temperate continental semi-arid monsoon climate zone. From May to October 2012 (approximately 50 years' post filling), prolong rainfall events ranging from $3-7$ days which triggered the failure across all infrastructure of the area at top and bottom of the slope. As prone to failure, which could affect living and transportation networks are the prime reasons for investigating the study area. 


\subsection{Geology}

The Fuxin area is mainly divided into the Bainaimio arc towards north and north china craton situated in the south, where NEE trending Chifeng-
Kaiyuan fault marks the boundary between them [5]. Lingyuan-Beipiao fault, trending NEE divides the NE north china craton into Liaoxi block (western Liaoning), Neimeng block (Inner Mongolia) [9].

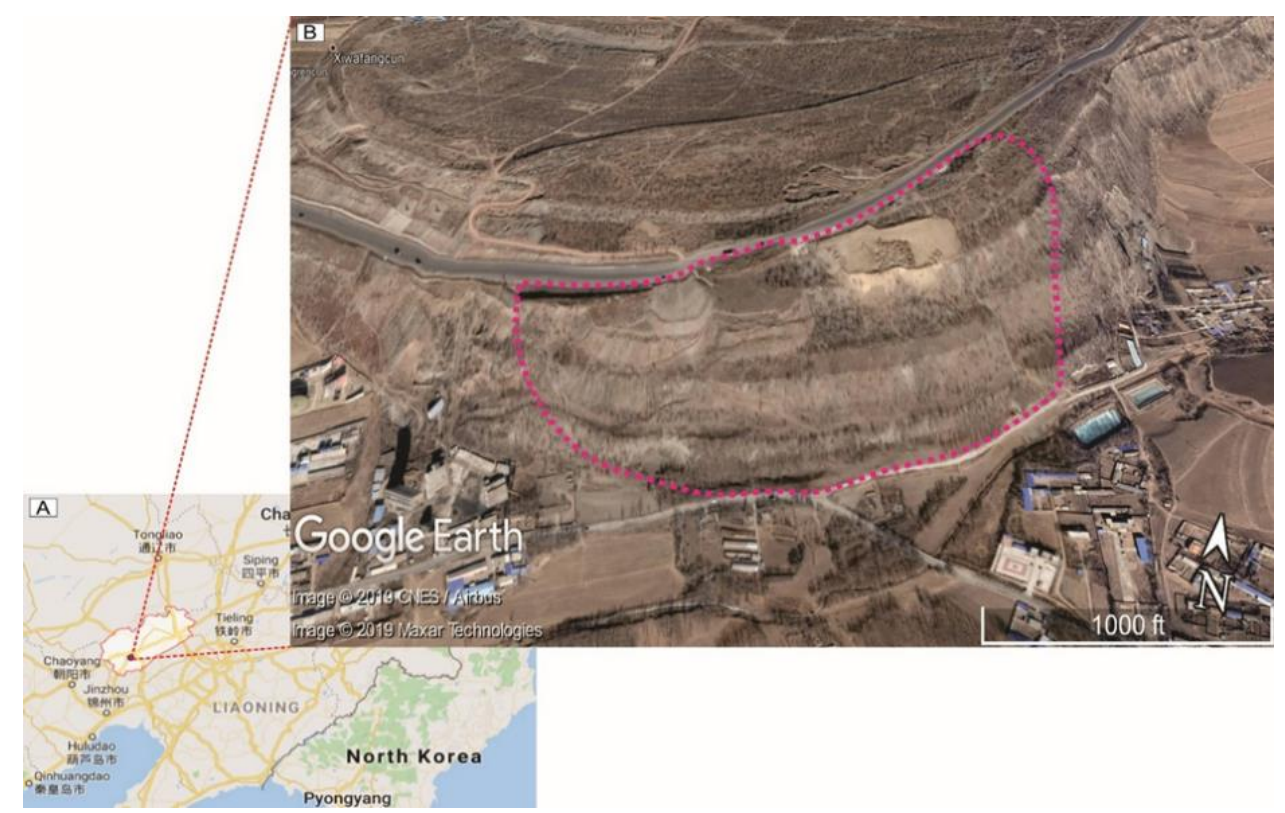

Figure 1. Location of the area under study (the area encircled is representing prominent failure).

The landform of the site under study (Figure. 1) in Fuxin is mainly hilly area which is piled up manually approximately 30 to $80 \mathrm{~m}$ with conglomerates and other related size boulders with underlain silty clay in an excavated open-pit mine for approximately 50 years ago. The outcrop of the slope area is predominantly composed of silty clay overlain by a conglomeratic unit where the sandstone of cretaceous Sunjiawan formation is probably representing the bedrock. The top view of the failure zone can be seen in (Figure. 2).

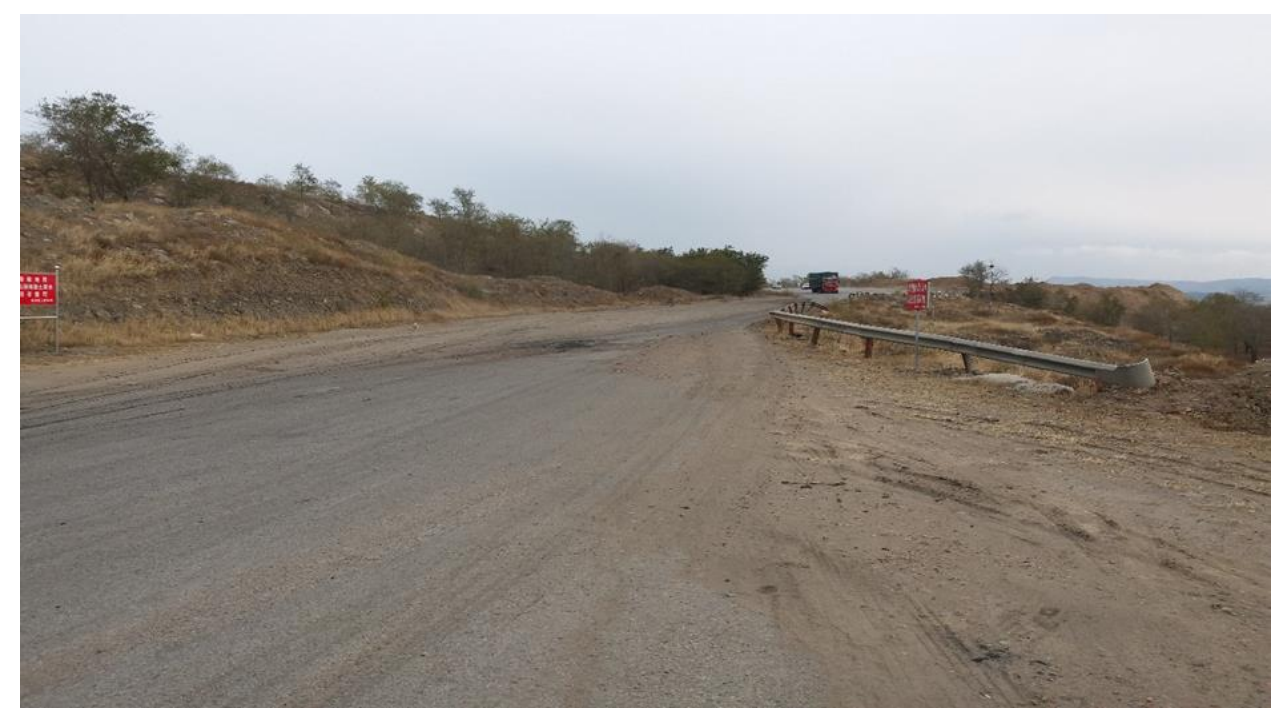

Figure 2. Field view of Fuxin Slide Zone near top of the slope.

The exposed conglomeratic unit of the slope is demonstrates the right and left overview of slope presented in (Figure. 3 (a), (b)) which clearly and composition of material in the study area. 


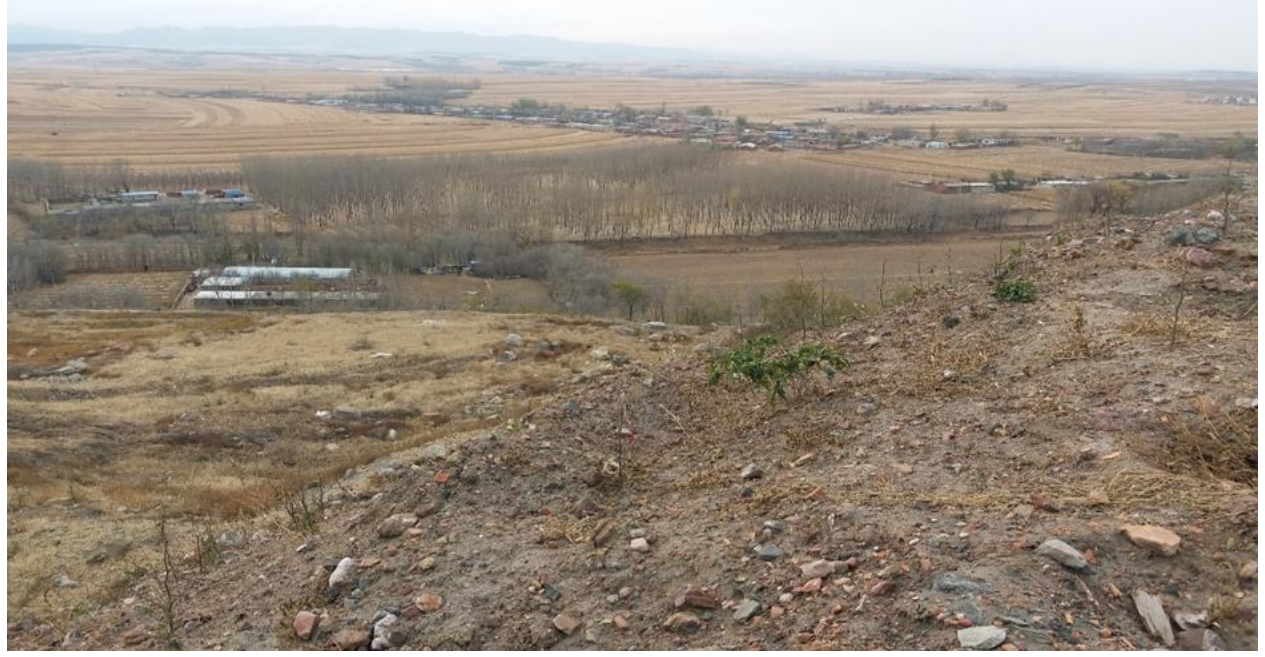

Figure 3 (a). Field view from right-top of Fuxin active slide failure zone.

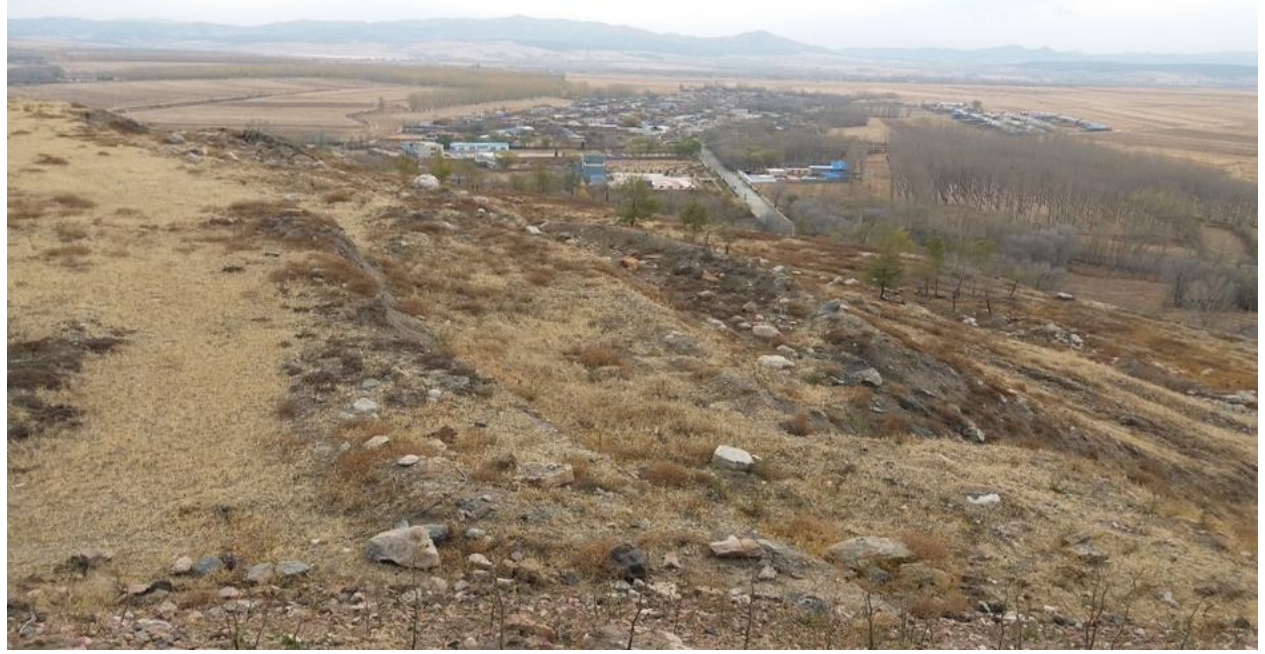

Figure 3 (b). Field view from left-top of Fuxin active slide failure zone.

The occurrence of this landslide in Fuxin is ob- the surroundings. The field view from bottom to served at middle-low level $(70-100 \mathrm{~m})$ from top of the failed slope can be seen in (Figure. 4). top to downward direction causing damages in

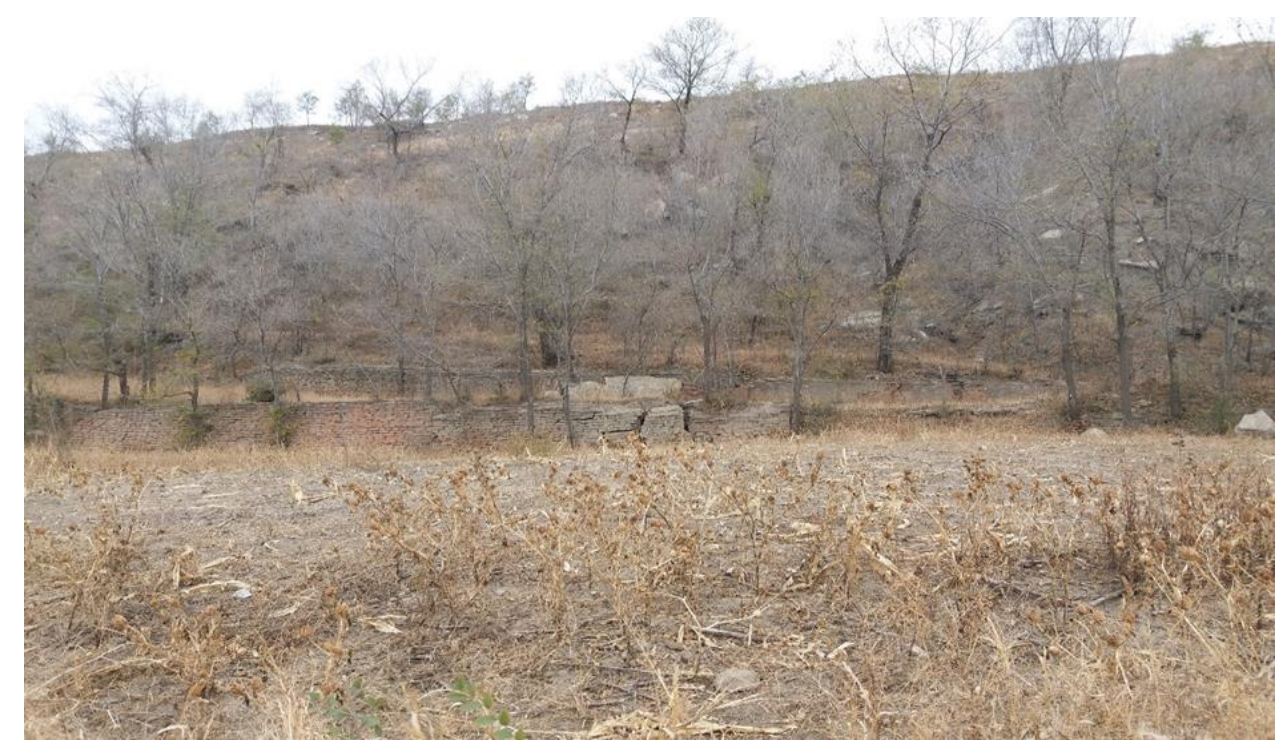

Figure 4. Field view from bottom to top of the failed slope (infrastructural damage can also be seen within the picture). 
Fractures developed as the results of tensile and observed at the top in conglomeratic outcrop of compressive strains generated due to overbur- failed slope in dry and snow seasons (Figure. 5 den stresses from the surroundings can be (a), (b)).

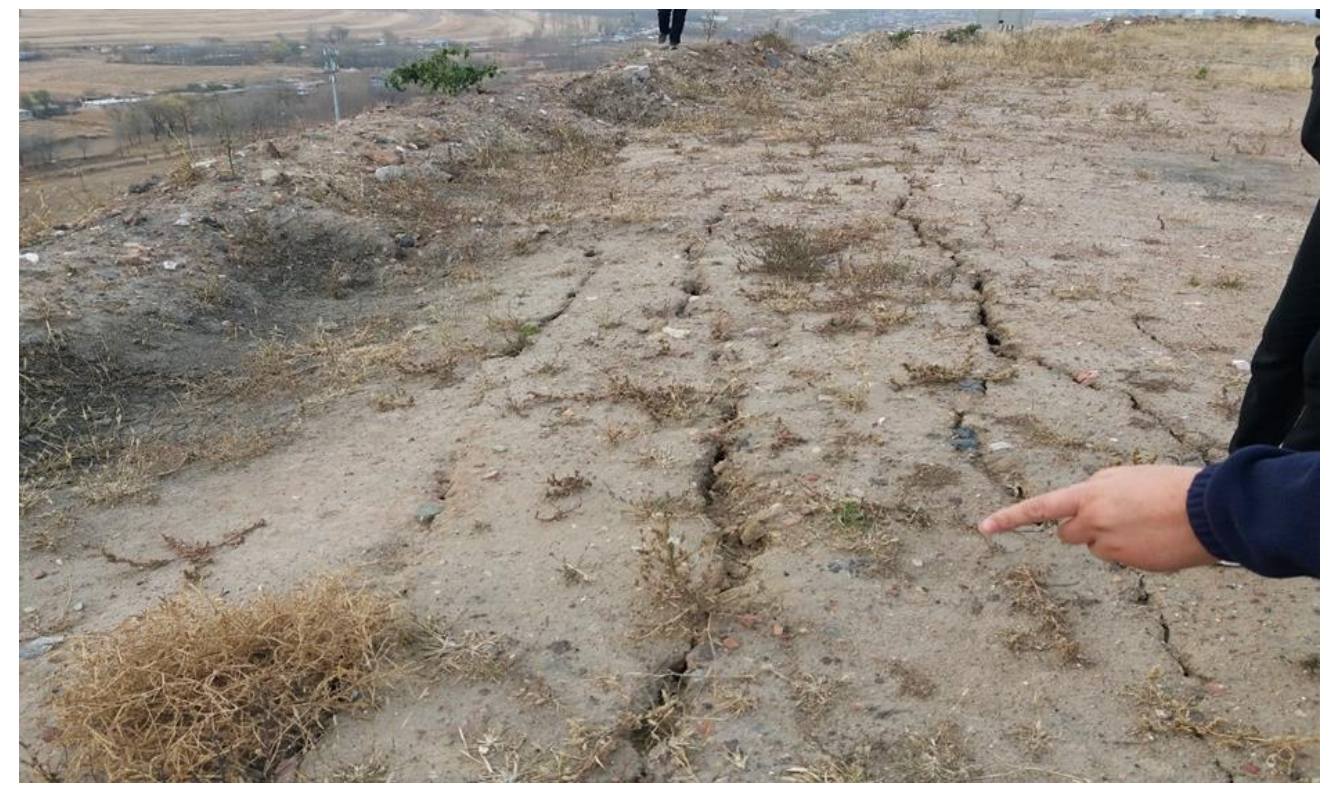

Figure 5 (a). Nearby view of cracks near slope surface in dry season.

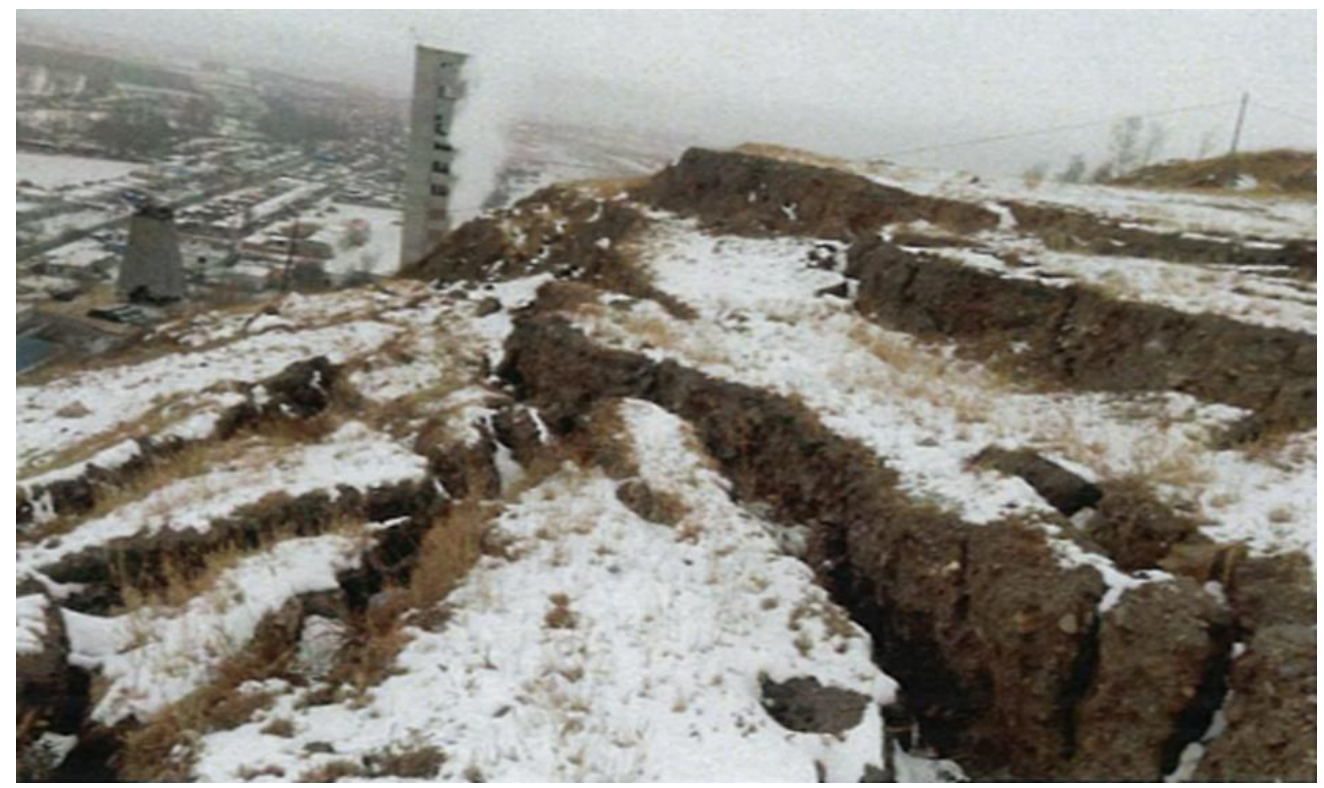

Figure 5 (b). Nearby view of downstream large cracks near slope surface in snow season.

\section{Scenario of landslide}

During the attempts made for the field investigation in the area, it is revealed that fewer small scars of landslide had developed after 50 years of post-artificial filling in the area. These slide scars were than become severe and enlarged after the extreme rainfall events in 2012. Presently, this slope failure in Fuxin area, West of Liaoning province has witnessed flowage in the form of sliding and movement of debris (various sizes of rock fragments including Sandstone, Silty clay and some related size large boulders). Large fractures nearby the roads at left and right bottom in the vicinity of the sliding zone have also been endangered which are observed during field investigation (Figure. 6 (a), (b)). The seasonal rainfall from May to October in the area further increase the risk of disaster.

The early spring in Northeast China is the snow melting season, this melting snow in Fuxin also 
increase the vulnerability of the failure zone as the snow water infiltrates within the large cracks of the sliding slope and as a result the shear strength of the slope is decreased, and also effect the vehicular traffic on the roads (which passes through the active slide zone) from early morning up to evening. The observed sliding mass, which is transported downstream have caused damage to agricultural fields and com $\mathrm{m}$ unity lands. Furthermore, most of the work places and shops are operational at day time and amphibious population of workers and tradespeople is in and around, also some people work in nearby fields, which particularly increase the risk element in this area as many people are exposed to severe risk. This residential area has witnessed flowage in the form of hollowing and bulging in the surroundings: as large cracks developed within the ground and also infrastructural damages occurred (Figures 7, 8 and 9). Moreover, these severe damages have also developed fewer more sliding zones in the area.

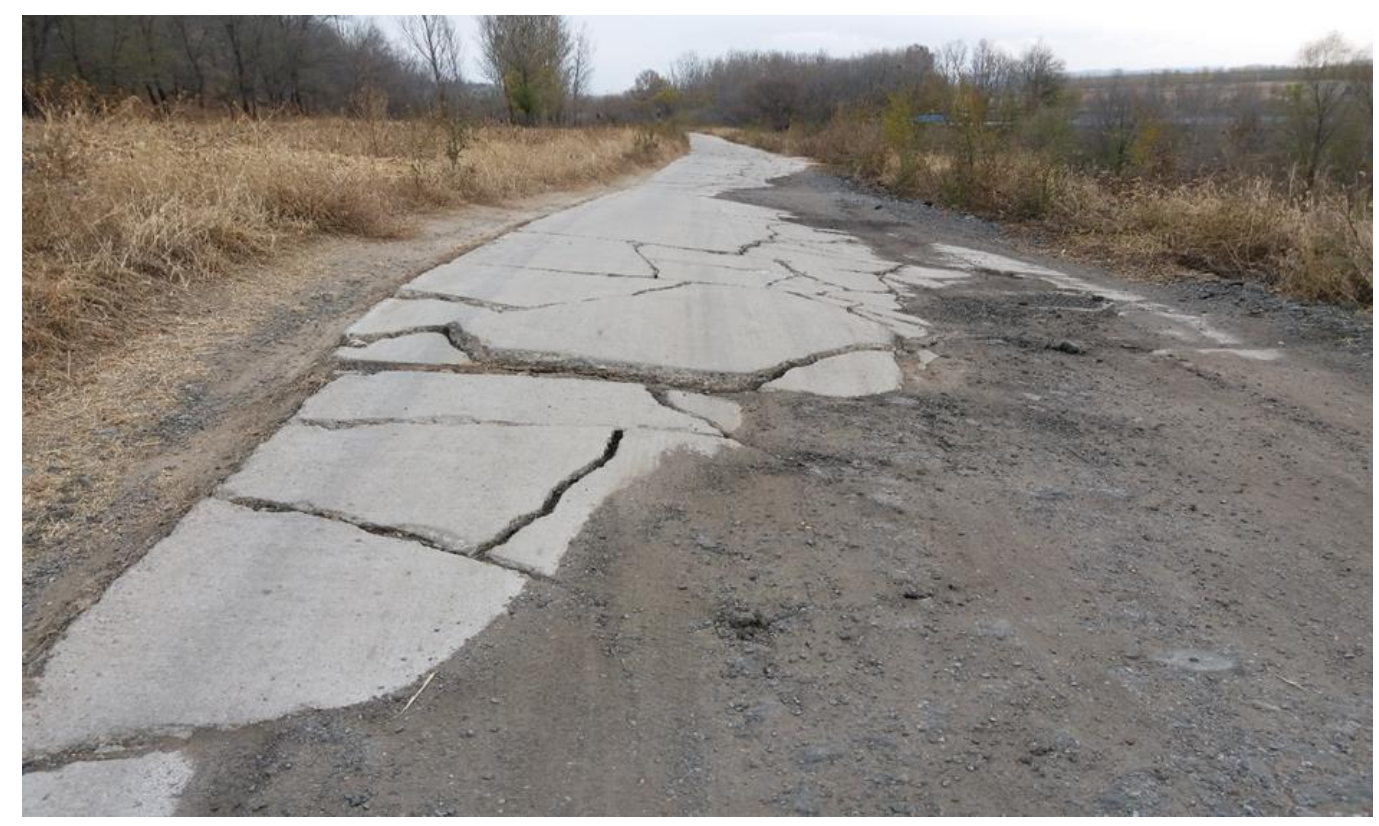

Figure 6 (a). Field view of damaged road at right-bottom of the failed slope in dry season.

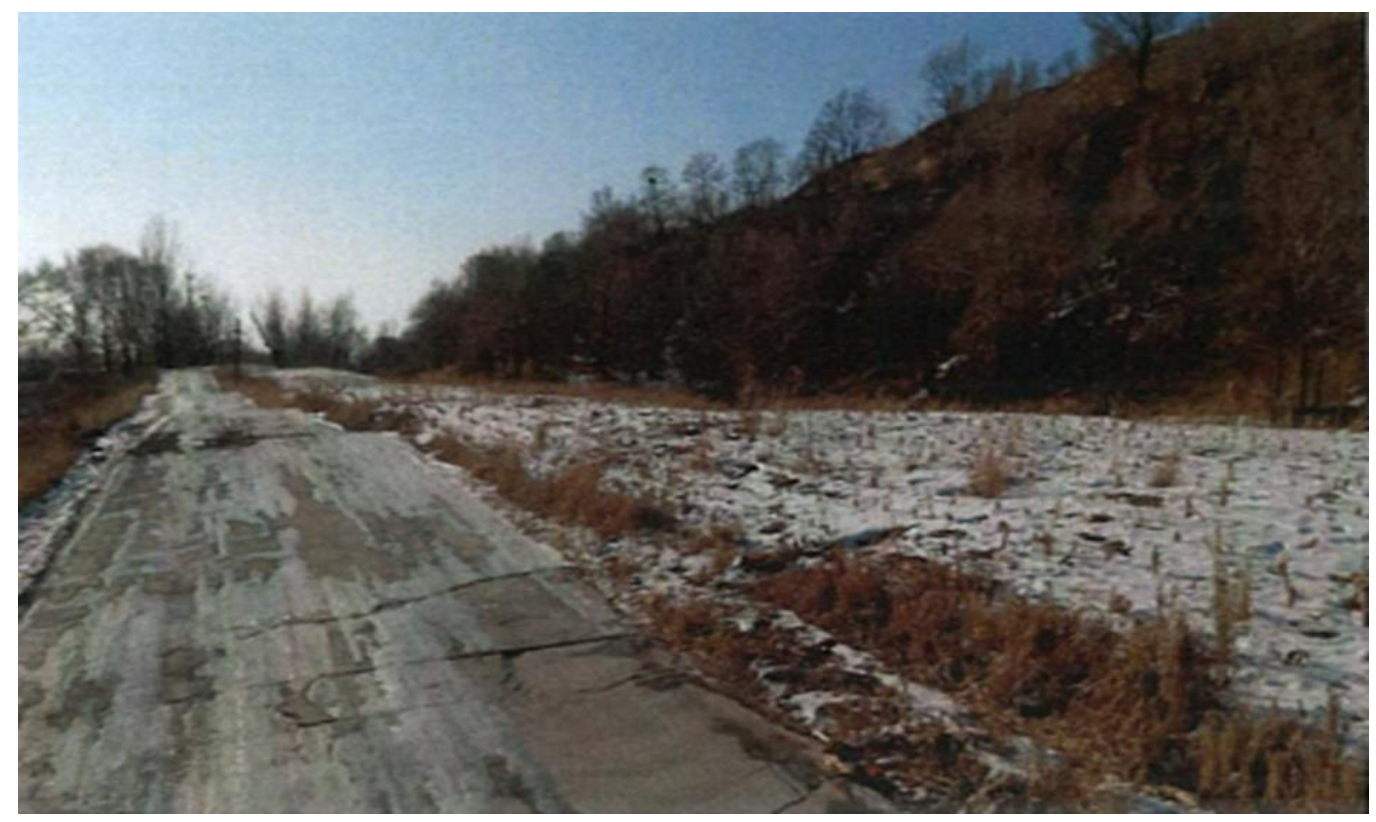

Figure 6 (b). Field view of damaged road at left-bottom of the failed slope in snow season. 


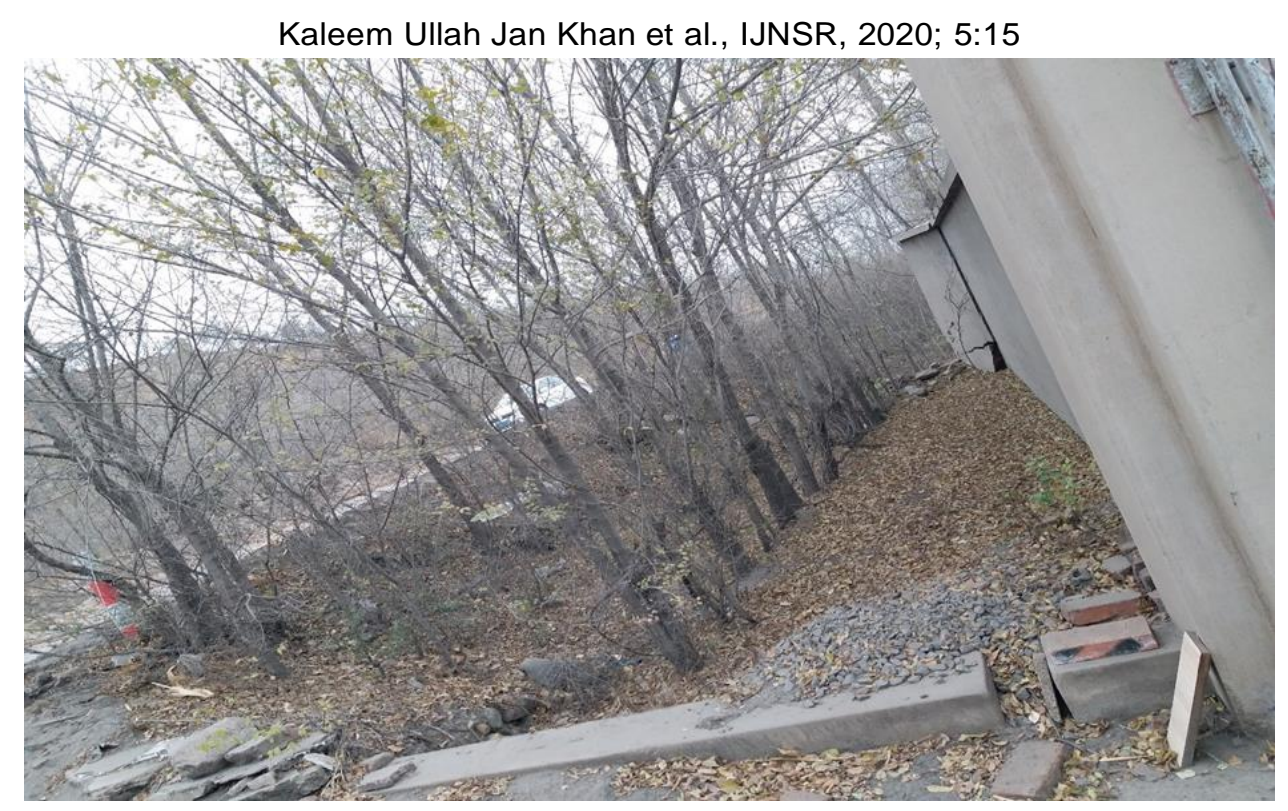

Figure 7. Field view of damaged wall of irrigation office building nearby the failed slope.

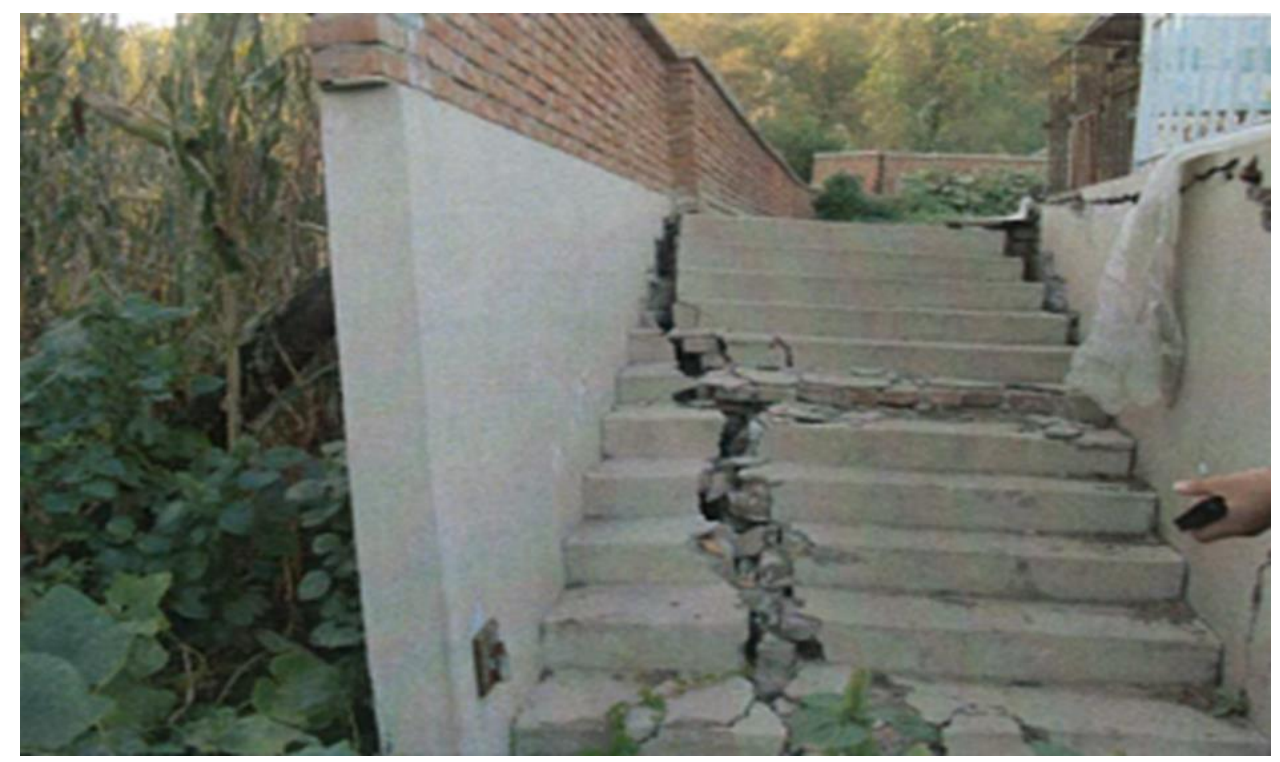

Figure 8. Field view of badly damaged stairs inside along the wall of irrigation office building nearby the failed slope.

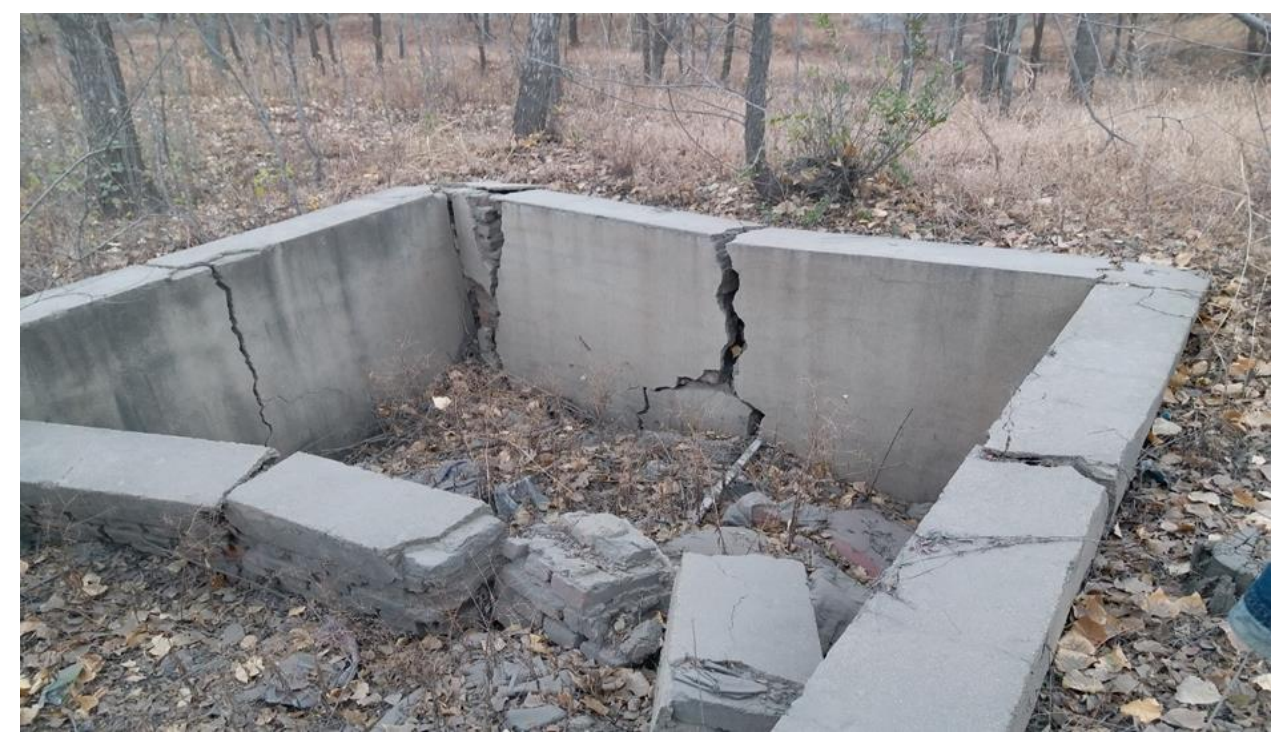

Figure 9. Field view of damaged water tank due to failure nearby the bottom of the slope. IJNSR: https://escipub.com/international-journal-of-natural-science-and-reviews/ 


\section{Mitigative measures to avoid the future disaster due to slope failure in Fuxin area}

In the recent years, the anthropogenic activities in the surroundings of sliding slope in Fuxin have increased the vulnerability of failure in the entire zone. The confluence road and infrastructural damages in the vicinity of failure zone can be seen in the pictures.

Some of the preventive measures to minimize

the future disaster in this sliding zone of Fuxin and its surroundings can be adopted as follows:

- There should be safe and planned disposal of materials for an artificial soil slope filling in the area.

- The slope should be modified wherever needed, especially in the zones with large fractures, to improve the stability.

- Construction of roads and buildings in the vicinity of the sliding zone without planning should be restricted to avoid economic loss.

- Mechanically stabilized embankments shouId be designed and constructed at the bottom of the slope to reduce movement of debris and to increase the safety of sliding slope.

- Blasting should be banned in the coal mines of Fuxin which are located in the vicinity of failure zone, instead the closely suitable strategy should be adopted for the purpose.

- In order to reduce the chance of failure, drainage system should be designed and improved through proper channel with the involvement of hydrologists for the diversion of seasonal rain water and melted snow.

\section{Conclusions}

The climatic factors as the excessive rainfall during summer and mid-autumn (May to October) including some geological factors, large fractures as observed near the surface having seepage zones together with the overburden stress resulted from the surrounding mountains: fragile slope witnessed instability due to these fostering factors in the area under study in Fuxin, Northeast China. The anthropogenic intervention as a diversion of rainfall water (natural drainage) and the overloading of the slope due to surrounding mountains when coupled with the augmenting natural factors renders the zone to potential landslide and debris movement in the future. The continuous applying loads of heavy moving vehicles and occurrence of prolonged rainfall events may suddenly trigger large failure in the area. Due to the high risk of slide in the area, both structural and non-structural measures for mitigation should be immediately taken to avoid the future disaster in Fuxin area. Local and provincial government committee for Disaster Management, Municipality and local communities should be involved in social awareness and policy making to actuate the surrounding population to abandon from building infrastructure without proper planning against the failure threats in the area, and the local population should also avoid unnecessary activities which are prone to failure. Construction and Public works divisions should jointly initiate structural measures for mitigation in the area.

\section{Acknowledgement}

This research was supported by National Natural Science Foundation of China (Grant Numbers. 41972267, 41572257, 41977221).

The authors are thankful to Liaoning Traffic Planning and Design Institute, Shenyang for help in providing the data about slope and geotechnical investigation.

\section{Disclosure statement}

There is no potentially conceivable conflict of interest reported by the authors.

\section{References}

[1] Richardson, B. Socio-technical Disasters: Profile and Prevalence. Disaster Prev. Manag. An Int. J. 1994, 3, 41-69, doi:10.1108/096535694100767 66.

[2] Aini, M.S.; Fakhru, A. Evolution of Emergency Management in Malaysia. 2001, 9, 46-53.

[3] Shaluf, I.M. Disaster types. Disaster Prev. Manag. An Int. J. 2007, 16, 704-717, doi:10.1108/09 653560710837019.

[4] UN/ISDR Living with Risk. 2002.

[5] Xiao, W.; Windley, B.F.; Hao, J.; Zhai, M. Accretion leading to collision and the Permian Solonker suture, Inner Mongolia, China: Termination of the central Asian orogenic belt. Tectonics 2003, doi:10.1029/2002tc001484. 
[6] Turner, B. A., \& Pidgeon, N. F. (1997). Manmade disasters. Butterworth-Heinemann.

[7] Denis, H. (1995). Scientists and disaster management. Disaster Prevention and Management: An International Journal.

[8] Keller, A. Z., \& Al-Madhari, A. F. (1996). Risk management and disasters. Disaster Prevention and Management: An International Journal.

[9] GEOLOGY, B. O. (1989). Regional Geology of Liaoning Province. 